\title{
Nomogram Including Elastography for Prediction of Contralateral Central Lymph Node Metastasis in Solitary Papillary Thyroid Carcinoma Preoperatively
}

This article was published in the following Dove Press journal:

Cancer Management and Research

\author{
Ning $\mathrm{Li}^{\prime}$ \\ Ju-hua $\mathrm{He}^{2}$ \\ Chao Song (D) $^{3}$ \\ Li-chun Yang ${ }^{4}$ \\ Hong-jiang Zhang' \\ Zhi-hai Li ${ }^{1}$ \\ 'Department of Ultrasound, Yunnan \\ Kungang Hospital, Kunming, Yunnan \\ Province, People's Republic of China; \\ ${ }^{2}$ Department of Function Examination, \\ Yunnan Provincial Hospital of Traditional \\ Chinese Medicine, Kunming, Yunnan \\ Province, People's Republic of China; \\ ${ }^{3}$ Department of Radiology, Yunnan \\ Kungang Hospital, Kunming, Yunnan \\ Province, People's Republic of China; \\ ${ }^{4}$ Department of Ultrasound, Yunnan \\ Cancer Hospital, Kunming, Yunnan \\ Province, People's Republic of China
}

Correspondence: Chao Song Department of Radiology, Yunnan Kungang Hospital, Kunming, Yunnan Province 650302, People's Republic of China

Tel +86-13908848395

Email songchaodr@aliyun.com

Li-chun Yang

Department of Ultrasound, Yunnan

Cancer Hospital, Kunming, Yunnan

Province 650118, People's Republic of

China

Tel +86-13888087336

Email yangchunli32I@I26.com
Background: It is controversial whether contralateral prophylactic central neck dissection (PCND) should be performed for patients with solitary and clinical lymph node negative $\left(\mathrm{cN}_{0}\right)$ papillary thyroid carcinoma (PTC) although routine ipsilateral PCND is required.

Objective: The aim of this study was to develop an improved nomogram including clinical features, ultrasound, and acoustic radiation force impulse (ARFI) elastography for the prediction of contralateral central lymph node metastasis (CLNM) in patients with solitary and $\mathrm{cN}_{0}$ PTC in the preoperative period.

Materials and Methods: A total of 340 patients were retrospectively included as the training cohort and 170 patients as the external validation cohort. Patients were grouped according to the pathological results of contralateral CLNM. The association between the clinical characteristics, ultrasound, and ARFI elastography and the risk for contralateral CLNM were analyzed. A nomogram was established based on the result of multivariable logistic analysis to predict the risk of contralateral CLNM, which was assessed by internal and external validation.

Results: CLNM was found in 213 patients (41.8\%), among whom 142 (27.8\%) had ipsilateral CLNM and 95 (18.6\%) had contralateral CLNM (including 68 (13.3\%) with bilateral CLNM). Multivariable analysis revealed that patients with younger age, male gender, larger tumor size, closer distance from the capsule, microcalcification, and larger $\mathrm{SWV}_{\text {mean }}$ were independent predictors associated with the contralateral CLNM $(P<0.05)$, which was served as the basis of the nomogram. It showed good discrimination (C-index: 0.856$)$ and calibration $\left(\chi^{2}=9.028\right.$, $P=0.340$, Hosmer-Lemeshow test) in the training cohort, and good discrimination was maintained in the external validation cohort (C-index: 0.792).

Conclusion: The nomogram utilizing the features of ultrasound combined with ARFI elastography in preoperatively predicting the risk of contralateral CLNM in patients with solitary and $\mathrm{cN}_{0}$ PTC was established, which showed superior performance both in internal and external validation.

Keywords: prophylactic central neck dissection, papillary thyroid carcinoma, central lymph node metastasis, acoustic radiation force impulse, nomogram

\section{Introduction}

Several studies have reported that the prevalence of central lymph node metastasis (CLNM) was 30\%-60\% in patients with clinical lymph node negative $\left(\mathrm{cN}_{0}\right)$ papillary thyroid carcinoma (PTC). ${ }^{1-4}$ Although, routine ipsilateral prophylactic central neck dissection (PCND) is required. ${ }^{5}$ A controversial topic is whether contralateral PCND 
should be performed in $\mathrm{cN}_{0}$ PTC patients with a solitary lesion in the unilateral lobe. It seemed to have little prognostic benefit but is supposed to increase morbidities such as hypoparathyroidism and recurrent laryngeal nerve injury. ${ }^{6-8}$

Due to the low accuracy of preoperative ultrasonography or CT in detecting CLNM, ${ }^{9-11}$ more and more studies have tried to predict CLNM by evaluating the clinicopathological characteristics of PTC. Previous studies have constructed several nomograms to predict CLNM by assessing clinicopathological features, including, but not limited to, younger age, male gender, larger tumor size, extrathyroid invasion, multifocality, and gene mutations, etc. ${ }^{12-15}$ Although these nomograms achieved good discrimination and calibration, they are limited in detecting CLNM in the preoperative period to avoid unnecessary PCND since most pathological factors are determined after surgery. Moreover, there are few studies on the prediction of the contralateral CLNM in patients with solitary and $\mathrm{cN}_{0}$ PTC (most studies focused on whether patients with low-risk PTC should omit PCND).

Ultrasound elastography has been widely applied to quantitatively evaluate tissue stiffness. Several studies reported that a higher elasticity index in thyroid nodules on acoustic radiation force impulse (ARFI) elastography or shear-wave ultrasound elastography is helpful to predict CLNM as an adjunct to conventional ultrasonography. ${ }^{16-18}$ However, to our knowledge, no nomogram includes elastography for predicting contralateral CLNM in patients with solitary and $\mathrm{cN}_{0}$ PTC preoperatively.

The purpose of this study was to establish an improved nomogram including clinical features, ultrasound, and ARFI elastography for the prediction of contralateral CLNM in patients with solitary and $\mathrm{cN}_{0}$ PTC in the preoperative period to help determine the extent of thyroid surgery.

\section{Materials and Methods}

\section{Patients}

This retrospective study was approved by the ethics committee of Yunnan Kungang Hospital (EC-20200203-1013). Written informed consents were obtained from all participants before surgery. This study was conducted in accordance with the declaration of Helsinki.

Preoperative ultrasonography and ARFI elastography for thyroid nodule has been routinely performed before the patients underwent surgery since 2015. From March 2015 to September 2019, 582 patients with $\mathrm{cN}_{0}$ PTC were observed. $\mathrm{cN}_{0}$ was defined as the absence of any of the following ultrasound features suggesting lymph node metastasis:1) ratio between the maximum longitudinal and transverse diameters $\leq 2 ; 2$ ) absence of echogenic hilum; 3) calcification; 4) cystic appearance; 5) focal cortical thickening; 6) granular parenchymal echoes; 7) hyperechoic punctuations; 8) presence of a peripheral vascularization. ${ }^{5}$ Patients with tumors in the isthmus, capsular invasion, multifocal disease, lateral lymph node metastases, distant metastases, and incomplete preoperative imaging data were excluded in this study. Finally, 510 patients with solitary and $\mathrm{cN}_{0}$ PTC were enrolled, which included 340 patients as the training cohort and 170 patients as the external validation cohort. All patients underwent thyroid lobectomy associated with bilateral PCND. The clinical variables, including age, gender, Hashimoto's thyroiditis, and family history of thyroid cancer were recorded. All patients were grouped according to the postoperative pathological results of the contralateral CLNM (Figure 1).

\section{Ultrasonography and ARFI Elastography}

Ultrasound scans were performed by S2000 ultrasound system (Siemens Medical Solutions, Mountain View, CA) with a 4-9 MHz linear transducer and Aplio 500 color ultrasound system (Toshiba Medical Systems Corporation, Otawara, Japan) with a $5-14 \mathrm{MHz}$ transducer. The ultrasonic assessments were performed by 2 sonographers with more than 10 years' experience in ultrasonography. The following ultrasound features were evaluated: tumor size $(\mathrm{mm})$, location (left or right lobe), distance from the capsule, echogenicity (hypo- or others), shape (regular or irregular), margin (well or poorly defined), halo sign, and calcification (microcalcifications, $<2 \mathrm{~mm}$ in diameter; macrocalcifications, $\geq 2 \mathrm{~mm}$ in diameter with shadowing, rim or eggshell calcification, or no calcification) ${ }^{19}$ (Figures $2 \mathrm{~A}$ and 2a). Besides, the internal flow was assessed by superb microvascular imaging (SMI) (classified as rich internal flow, rare internal flow, or no visible flow) since color Doppler was insensitive in lowspeed vascular signal (Figures $2 \mathrm{~B}$ and $2 \mathrm{~b}$ ).

ARFI elastography was subsequently evaluated for the selected tumor. The elastic images were stored on a longitudinal plane. Under virtual touch tissue (VTI) mode, VTI and grayscale ultrasound were displayed simultaneously. The VTI area ratio (VAR) was obtained by the ratio of nodule areas on VTI and grayscale ultrasound (area on VTI/grayscale ultrasound) (Figures 2C and 2c). Quantitative measurement of elasticity was achieved on each virtual touch tissue quantification (VTIQ) image with a rectangular region of interest (ROI) located over the stiffest part of the lesion after a high shear wave quality 

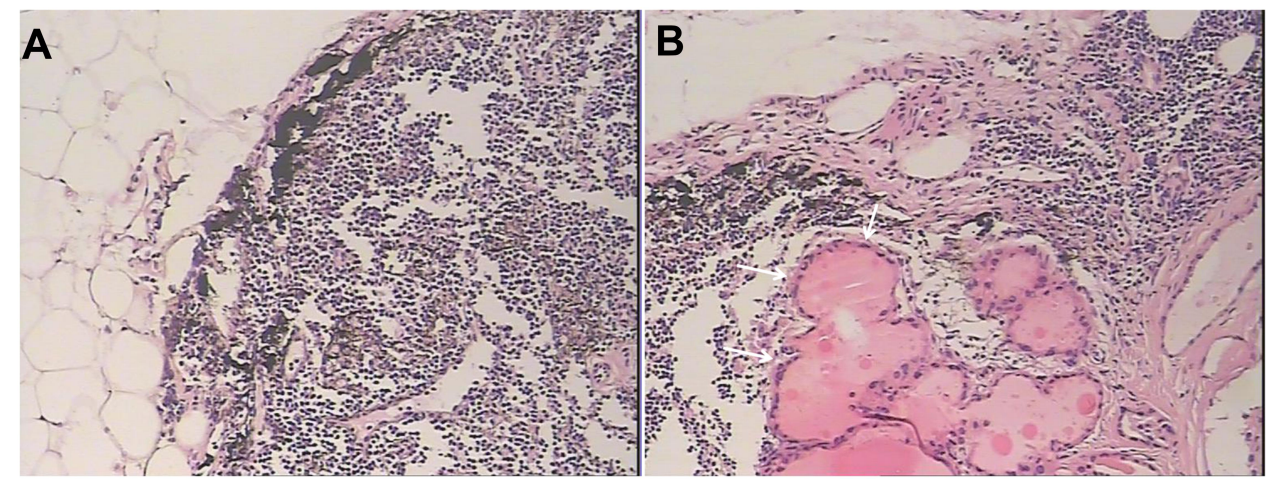

Figure I Postoperative histopathology of the contralateral CLNM (haematoxylin-eosin stain, $\times 100$ magnification). CLNM was not found in figure (A) but confirmed in figure (B) (marked by arrows).

Abbreviation: CLMN, central lymph node metastasis.

was obtained (Figures $2 \mathrm{D}$ and $2 \mathrm{~d}$ ). The shear wave velocity $(\mathrm{SWV}, \mathrm{m} / \mathrm{s})$ in the ROI was calculated automatically (Figures $2 \mathrm{E}$ and $2 \mathrm{e})$. The mean $\mathrm{SWV}$ value $\left(\mathrm{SWV}_{\text {mean }}\right)$ was obtained after averaging each SWV values in the ROI.

\section{Statistical Analysis}

The statistical analyses were performed with SPSS (version 22.0; SPSS Inc., Chicago, IL, USA), Medcalc software (version 11.0, Ostend, Belgium), and R package version 3.6.2. The numerical data were expressed as median (interquartile range) for abnormal distribution, and the categorical variables were expressed as number (percentage). In the training cohort, clinical and ultrasonic variables were first analyzed by univariate logistic regression analysis. The predictors that were significant at $P<0.05$ in the univariate analysis included in the multivariate logistic regression. A nomogram was established based on the independent predictors identified by the multivariable analysis to predict the risk of contralateral CLNM. The performance of the nomogram was internally validated with Bootstrap resampling (1000 times) analysis. ${ }^{20}$ HosmerLemeshow test was used for calibration. To evaluate the internal and external discrimination of the nomogram, the area under the curve (AUC) of receiver operating characteristic curve (ROC), also known as Harrell's concordance index $(\mathrm{C} \text {-index })^{21}$ was assessed in both internal and external validation (based on the validation cohort).

\section{Results}

\section{Clinical Characteristics of Patients with Solitary and $\mathrm{cN}_{0}$ PTC in the Training and Validation Cohorts}

A total of 510 patients with solitary and $\mathrm{cN}_{0}$ PTC were confirmed after surgery. CLNM was present in 213 patients
(41.8\%), among whom 142 (27.8\%) had ipsilateral CLNM, and 95 (18.6\%) had contralateral CLNM (including 68 (13.3\%) with bilateral CLNM). The training cohort consisted of 340 patients, of which 63 patients with contralateral CLNM were included in the CLNM+ group, while the remained 277 patients were included in the CLNM-group. The validation cohort included 170 patients, of which 32 patients were included in the CLNM+ group and 138 patients in the CLNM-group. The clinical features of PTC patients in both training and validation cohorts are shown in Table 1. No significant difference was found in the basic clinical characteristics between the training and validation cohorts, which verified homogeneous baseline data between the two cohorts.

\section{Univariate and Multivariable Analysis on the Predictors of Contralateral CLNM}

Univariate analysis indicated that the predictors such as younger age, male gender, closer distance from the capsule, larger tumor size, and microcalcification were significantly associated with the risk of contralateral CLNM (Table 2). The tumor stiffness of the CLNM+ group was generally greater than that of the CLNM-group, and the VAR of the lesion was generally larger than in the grayscale image. Table 2 shows that $\mathrm{SWV}_{\text {mean }}$ and VAR $>1$ were associated with the risk for contralateral CLNM.

Multivariable analysis conducted using a logistic regression model further revealed that patients with younger age $(O R=0.876, P<0.001)$, male gender $(O R=2.372$, $P=0.029)$, larger tumor size $(O R=2.814, P<0.001)$, closer distance from the capsule $(O R=0.176, P<0.001)$, microcalcification $(O R=2.648, P=0.037)$, and $\mathrm{SWV}_{\text {mean }}$ $(O R=9.516, P<0.001)$ were found to be independent predictors associated with the contralateral CLNM (Table 2). 


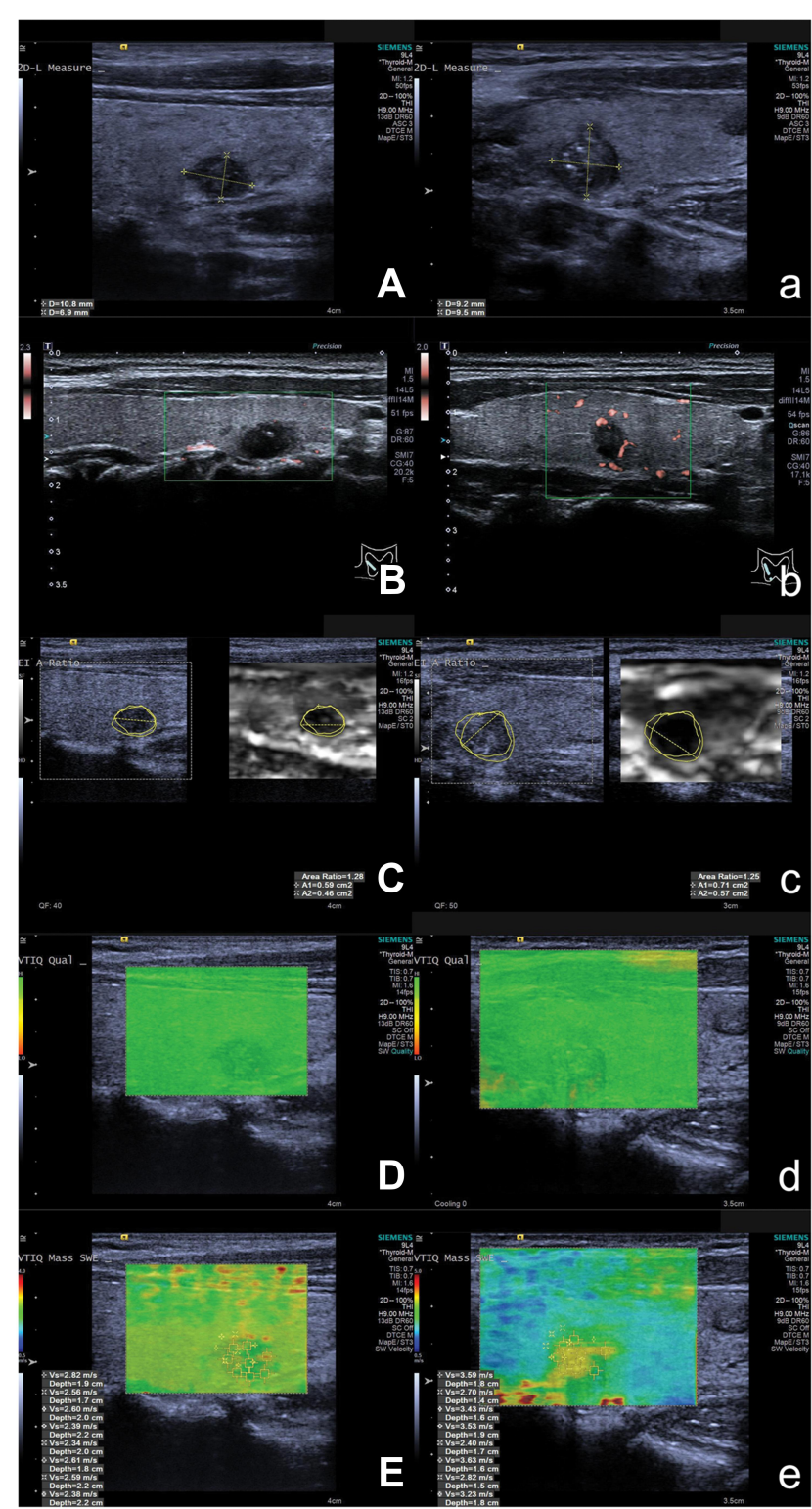

Figure 2 Ultrasound and ARFI elastography images of patients with solitary and $\mathrm{CN}_{0}$ PTC. Figures (A-E) are images of contralateral CLMN in patients with solitary and $\mathrm{cN}_{0}$ PTC, while Figures (a) to (e) are images without contralateral CLMN. Grayscale ultraound, SMI, VAR displayed on VTI, ARFI quality mode, VTIQ are showed in figures (A) and (a), (B) and (b), (C) and (c), (D) and (d), and (E) and (e). The images of grayscale ultrasound, SMI, and VAR are similar between patients with or without contralateral CLMN. However, the SWV mean of patient with contralateral CLMN $(3.17 \mathrm{~m} / \mathrm{s})$ displayed on VTIQ is higher than that of patient without contralateral CLMN $(2.54 \mathrm{~m} / \mathrm{s})$

Abbreviations: ARFI, acoustic radiation force impulse; $\mathrm{cN}_{0}$, clinical lymph node negative; PTC, papillary thyroid carcinoma; CLMN, central lymph node metastasis; SMI, superb microvascular imaging; VTI, virtual touch tissue; VTIQ, virtual touch tissue quantification; VAR, virtual touch tissue area ratio; SWV, shear wave velocity.

\section{Nomogram for Predicting Contralateral CLNM in Patients with Solitary and $\mathrm{cN}_{0}$ PTC}

A nomogram with the 6 independent predictors associated with contralateral CLNM was constructed (Figure 3). Each predictor was proportionally assigned a specific number within a 0 - to 100 -point scale. By adding the total score and locating it on the total point scale, the estimated incidence of contralateral CLNM in patients with solitary and $\mathrm{cN}_{0}$ PTC was determined.

\section{Internal and External Validation of the Nomogram}

The bia-corrected C-index of the nomogram created from the training cohort was 0.856 ( $95 \%$ CI 0.814 to 0.891 ), demonstrating good discrimination $(>0.75)$ (Figure 4A). The test of calibration indicated no significant lack of departure $\left(\chi^{2}=9.028, \mathrm{P}=0.340\right.$, Hosmer-Lemeshow test), which demonstrated good calibration of the nomogram. To validate the usefulness of the nomogram, the external validation cohort consisted of 170 patients with a $19 \%$ overall rate of contralateral CLMN. When applied to the original model, the C-index generated from the external validation data was $0.792(95 \% \mathrm{CI}, 0.793$ to 0.857$)$, demonstrating good discrimination power in the validation cohort (Figure 4B).

\section{Discussion}

The present study revealed that higher stiffness of PTC was associated with contralateral CLNM, which demonstrated the utility of preoperative ARFI elastography for contralateral CLNM in patients with solitary and $\mathrm{cN}_{0}$ PTC. This study included 15 variables from clinical characteristics, ultrasound, and ARFI elastography as potential predictors for contralateral CLNM. The results indicated that the presence of contralateral CLNM was associated with the features such as younger age, male gender, larger tumor size, closer distance from the capsule, microcalcification, as well as larger $\mathrm{SWV}_{\text {mean }}$. The developed nomogram based on the training cohort showed good discrimination and satisfied calibration. Good discrimination was maintained when applying this nomogram to predict the contralateral CLMN of the external validation cohort. These results validated that the nomogram showed good performance for predicting contralateral CLNM in patients with solitary and $\mathrm{cN}_{0}$ PTC.

\section{Presence of Ipsilateral and Contralateral CLNM in Patients with Solitary and $\mathrm{CN}_{0}$ PTC}

CLNM usually occurs first in the ipsilateral central compartment and then spread to the contralateral central and 
Table I Clinical, Ultrasonic, and ARFI Elastographical Characteristics of PTC Patients in the Training and Validation Cohorts

\begin{tabular}{|c|c|c|c|c|c|c|c|}
\hline \multirow{2}{*}{\multicolumn{2}{|c|}{ Variables }} & \multicolumn{3}{|c|}{ Training Cohort } & \multicolumn{3}{|c|}{ Validation Cohort } \\
\hline & & $\begin{array}{l}\text { Overall } \\
(n=340)\end{array}$ & $\begin{array}{l}\text { CLNM- Group } \\
(n=277)\end{array}$ & $\begin{array}{l}\text { CLNM+ Group } \\
(n=63)\end{array}$ & $\begin{array}{l}\text { Overall } \\
(n=170)\end{array}$ & $\begin{array}{l}\text { CLNM- Group } \\
(n=138)\end{array}$ & $\begin{array}{l}\text { CLNM+ Group } \\
(n=32)\end{array}$ \\
\hline \multicolumn{2}{|l|}{ Age } & $36(31,42)$ & $38(33,43)$ & $32(27,34)$ & $36(31.8,42)$ & $37(33,42)$ & $31.5(26.35)$ \\
\hline Gender & $\begin{array}{l}\text { Female } \\
\text { Male }\end{array}$ & $\begin{array}{l}272(80.0 \%) \\
68(20.0 \%)\end{array}$ & $\begin{array}{l}228(82.3 \%) \\
49(17.7 \%)\end{array}$ & $\begin{array}{l}44(69.8 \%) \\
19(30.2 \%)\end{array}$ & $\begin{array}{l}\text { I37 (80.6\%) } \\
33(19.4 \%)\end{array}$ & $\begin{array}{l}115(83.3 \%) \\
23(16.7 \%)\end{array}$ & $\begin{array}{l}22(68.7 \%) \\
10(31.3 \%)\end{array}$ \\
\hline \multicolumn{2}{|c|}{ Hashimoto's thyroiditis } & $102(30.0 \%)$ & 89 (32.1\%) & $13(20.6 \%)$ & $51(30.0 \%)$ & $46(33.3 \%)$ & $5(15.6 \%)$ \\
\hline \multicolumn{2}{|c|}{ Family history of thyroid cancer } & $34(10.0 \%)$ & $28(10.1 \%)$ & $6(9.5 \%)$ & $14(8.2 \%)$ & II (8.0\%) & $3(9.4 \%)$ \\
\hline \multicolumn{2}{|c|}{ Tumor size $(\mathrm{mm})$} & $6(5,8)$ & $6(5,7)$ & $8(7,10)$ & $6(5,9)$ & $6(4,7)$ & $8(7,11)$ \\
\hline Location & $\begin{array}{l}\text { Left } \\
\text { Right }\end{array}$ & $\begin{array}{l}163(47.9 \%) \\
177(52.1 \%)\end{array}$ & $\begin{array}{l}138(49.8 \%) \\
139(50.2 \%)\end{array}$ & $\begin{array}{l}25(39.7 \%) \\
38(60.3 \%)\end{array}$ & $\begin{array}{l}83(48.8 \%) \\
87(51.2 \%)\end{array}$ & $\begin{array}{l}65(47.1 \%) \\
73(52.9 \%)\end{array}$ & $\begin{array}{l}18(56.3 \%) \\
14(43.8 \%)\end{array}$ \\
\hline \multicolumn{2}{|c|}{ Distance from the capsule $(\mathrm{mm})$} & $1.5(1.1,1.9)$ & $1.6(1.1,2.0)$ & I.I $(0.7,1.6)$ & $1.5(1.0,2.1)$ & $1.6(1.1,2.1)$ & $1.2(0.7,1.6)$ \\
\hline Echogenicity & $\begin{array}{l}\text { Hypo- } \\
\text { Others }\end{array}$ & $\begin{array}{l}323(95.0 \%) \\
17(5.0 \%)\end{array}$ & $\begin{array}{l}262(94.6 \%) \\
15(5.4 \%)\end{array}$ & $\begin{array}{l}61 \text { (96.8\%) } \\
2(3.2 \%)\end{array}$ & $\begin{array}{l}159(93.5 \%) \\
\text { II (6.5\%) }\end{array}$ & $\begin{array}{l}129(93.5 \%) \\
9(6.5 \%)\end{array}$ & $\begin{array}{l}30(93.8 \%) \\
2(6.3 \%)\end{array}$ \\
\hline Shape & $\begin{array}{l}\text { Regular } \\
\text { Irregular }\end{array}$ & $\begin{array}{l}171(50.3 \%) \\
169(49.7 \%)\end{array}$ & $\begin{array}{l}140(50.5 \%) \\
137(49.5 \%)\end{array}$ & $\begin{array}{l}31 \text { (49.2\%) } \\
32 \text { (50.8\%) }\end{array}$ & $\begin{array}{l}83 \text { (48.8\%) } \\
87 \text { (51.2\%) }\end{array}$ & $\begin{array}{l}70(50.7 \%) \\
68(49.3 \%)\end{array}$ & $\begin{array}{l}13(40.6 \%) \\
19(59.4 \%)\end{array}$ \\
\hline Margin & $\begin{array}{l}\text { Well defined } \\
\text { Pooly defined }\end{array}$ & $\begin{array}{l}114(33.5 \%) \\
226(66.5 \%)\end{array}$ & $\begin{array}{l}89(32.1 \%) \\
188(67.9 \%)\end{array}$ & $\begin{array}{l}25(39.7 \%) \\
38(60.3 \%)\end{array}$ & $\begin{array}{l}48(28.2 \%) \\
122(71.8 \%)\end{array}$ & $\begin{array}{l}41(29.7 \%) \\
97(70.3 \%)\end{array}$ & $\begin{array}{l}7(21.9 \%) \\
25(78.1 \%)\end{array}$ \\
\hline \multicolumn{2}{|l|}{ Halo sign } & $28(8.2 \%)$ & $21(7.6 \%)$ & 7 (11.1\%) & $15(8.8 \%)$ & $13(9.4 \%)$ & $2(6.3 \%)$ \\
\hline Calcification & $\begin{array}{l}\text { Microcalcification } \\
\text { Macrocalcification } \\
\text { Eggshell } \\
\text { calcification } \\
\text { No calcification }\end{array}$ & $\begin{array}{l}86(25.3 \%) \\
15(4.4 \%) \\
0(0 \%) \\
239(70.3 \%)\end{array}$ & $\begin{array}{l}64(23.1 \%) \\
11(4.0 \%) \\
0(0 \%) \\
202(72.9 \%)\end{array}$ & $\begin{array}{l}22(34.9 \%) \\
4(6.3 \%) \\
0(0 \%) \\
37(58.7 \%)\end{array}$ & $\begin{array}{l}39(22.9 \%) \\
9(52.9 \%) \\
0(0 \%) \\
122(71.8 \%)\end{array}$ & $\begin{array}{l}27(19.6 \%) \\
7(5.1 \%) \\
0(0 \%) \\
104(75.4 \%)\end{array}$ & $\begin{array}{l}12(37.5 \%) \\
2(6.3 \%) \\
0(0 \%) \\
18(56.3 \%)\end{array}$ \\
\hline SMI & $\begin{array}{l}\text { No visible flow) } \\
\text { Rare internal flow } \\
\text { Rich internal flow }\end{array}$ & $\begin{array}{l}25(7.4 \%) \\
248(72.9 \%) \\
67(19.7 \%)\end{array}$ & $\begin{array}{l}21 \text { (7.6\%) } \\
202(72.9 \%) \\
54(19.5 \%)\end{array}$ & $\begin{array}{l}4(6.3 \%) \\
46(73.0 \%) \\
13(20.6 \%)\end{array}$ & $\begin{array}{l}17(10.0 \%) \\
126(74.1 \%) \\
27(15.9 \%)\end{array}$ & $\begin{array}{l}14(10.1 \%) \\
103(74.6 \%) \\
21(15.2 \%)\end{array}$ & $\begin{array}{l}3(9.4 \%) \\
23(71.9 \%) \\
6(18.8 \%)\end{array}$ \\
\hline \multicolumn{2}{|l|}{$S W V_{\text {mean }}$} & $\begin{array}{l}2.99(2.53 \\
3.38)\end{array}$ & $2.85(2.46,3.27)$ & $3.44(3.07,3.95)$ & $\begin{array}{l}2.72(2.37 \\
3.18)\end{array}$ & $2.58(2.26,3.07)$ & $3.12(2.95,3.68)$ \\
\hline \multicolumn{2}{|l|}{ VAR $>1$} & $264(77.6 \%)$ & $209(75.5 \%)$ & 55 (87.3\%) & $129(75.9 \%)$ & $102(73.9 \%)$ & 27 (84.4\%) \\
\hline
\end{tabular}

Abbreviations: ARFI, acoustic radiation force impulse; PTC, papillary thyroid carcinoma; SMI, superb microvascular imaging; SWV, shear wave velocity; VAR, virtual touch tissue area ratio.

ipsilateral lateral compartments. ${ }^{22}$ It is controversial whether contralateral PCND is needed if patients with solitary and $\mathrm{cN}_{0}$ PTC. ${ }^{23}$ The result of this study revealed that $27.8 \%$ of patients with solitary and $\mathrm{cN}_{0}$ PTC found ipsilateral CLNM while $18.6 \%$ of patients had contralateral CLNM, which is similar to the meta-analysis by Sun et $^{2}{ }^{24}(25 \%-63.83 \%$ for ipsilateral CLNM and $9.24 \%-30.6 \%$ for contralateral CLNM). Thus, we believe that ipsilateral PCND should be routinely performed. Meanwhile, it is significant that patients should be stratified according to the risk of contralateral CLNM, and bilateral PCND was performed only in high-risk patients with contralateral CLNM to reduce the possibility of recurrence and reoperation.

\section{Predictors of Contralateral CLNM in Patients with Solitary and $\mathrm{cN}_{0}$ PTC}

Until now, few nomograms are developed to predict the contralateral CLNM of patients with low-risk PTC. Most of the researches utilized nomograms for the prediction of the risk of CLNM to help surgeons make appropriate decisions on whether PCND is warranted. ${ }^{12-15}$ Hei et $\mathrm{al}^{25}$ constructed a nomogram integrating 3 variables such as tumor size, 
Table 2 Univariate and Multivariable Logistic Analysis for Predicting Contralateral CLMN in Patients with Solitary and cN 0 PTC

\begin{tabular}{|c|c|c|c|c|c|c|c|}
\hline \multicolumn{2}{|l|}{ Predictors } & \multicolumn{3}{|c|}{ Univariate Analysis } & \multicolumn{3}{|c|}{ Multivariable Analysis } \\
\hline & & $P$ & OR & $95 \% \mathrm{Cl}$ & $\mathbf{P}$ & OR & $95 \% \mathrm{Cl}$ \\
\hline Age & & $<0.001$ & 0.865 & $0.823-0.909$ & $<0.001$ & 0.876 & $0.830-0.924$ \\
\hline Gender & $\begin{array}{l}\text { Female } \\
\text { Male }\end{array}$ & 0.027 & $\begin{array}{l}\text { Reference } \\
2.009\end{array}$ & $\mathrm{I} .08 \mathrm{I}-3.736$ & 0.029 & $\begin{array}{l}\text { Reference } \\
2.372\end{array}$ & $1.092-5.152$ \\
\hline \multicolumn{2}{|c|}{ Hashimoto's thyroiditis } & 0.075 & 0.549 & $0.284-1.063$ & & & \\
\hline \multicolumn{2}{|c|}{ Family history of thyroid cancer } & 0.889 & 0.936 & $0.370-2.367$ & & & \\
\hline \multicolumn{2}{|c|}{ Tumor size $(\mathrm{mm})$} & $<0.001$ & 2.942 & $2.206-3.923$ & $<0.001$ & 2.814 & $1.940-4.084$ \\
\hline Location & $\begin{array}{l}\text { Left } \\
\text { Right }\end{array}$ & 0.148 & $\begin{array}{l}\text { Reference } \\
1.509\end{array}$ & $0.865-2.634$ & & & \\
\hline \multicolumn{2}{|c|}{ Distance from the capsule $(\mathrm{mm})$} & $<0.001$ & 0.178 & $0.096-0.329$ & $<0.001$ & 0.176 & $0.070-0.446$ \\
\hline Echogenicity & $\begin{array}{l}\text { Hypo- } \\
\text { Others }\end{array}$ & 0.472 & $\begin{array}{l}\text { Reference } \\
0.576\end{array}$ & $0.128-2.593$ & & & \\
\hline Shape & $\begin{array}{l}\text { Regular } \\
\text { Irregular }\end{array}$ & 0.801 & $\begin{array}{l}\text { Reference } \\
1.073\end{array}$ & $0.619-1.861$ & & & \\
\hline Margin & $\begin{array}{l}\text { Well defined } \\
\text { Pooly defined }\end{array}$ & 0.224 & $\begin{array}{l}\text { Reference } \\
0.703\end{array}$ & $0.399-|.24|$ & & & \\
\hline \multicolumn{2}{|l|}{ Halo sign } & 0.331 & 1.569 & $0.633-3.891$ & & & \\
\hline Calcification & $\begin{array}{l}\text { No calcification } \\
\text { Microcalcification } \\
\text { Macrocalcification }\end{array}$ & $\begin{array}{l}0.039 \\
0.261\end{array}$ & $\begin{array}{l}\text { Reference } \\
1.877 \\
1.985\end{array}$ & $\begin{array}{l}1.032-3.412 \\
0.600-6.570\end{array}$ & 0.037 & $\begin{array}{l}\text { Reference } \\
2.648\end{array}$ & $1.060-6.618$ \\
\hline SMI & $\begin{array}{l}\text { No visible flow } \\
\text { Rare internal flow } \\
\text { Rich internal flow }\end{array}$ & $\begin{array}{l}0.754 \\
0.709\end{array}$ & $\begin{array}{l}\text { Reference } \\
\text { I.196 } \\
\text { I. } 264\end{array}$ & $\begin{array}{l}0.392-3.650 \\
0.370-4.319\end{array}$ & & & \\
\hline $\begin{array}{l}S W V_{\text {mean }} \\
V A R>1\end{array}$ & & $\begin{array}{l}<0.001 \\
0.046\end{array}$ & $\begin{array}{l}6.756 \\
2.237\end{array}$ & $\begin{array}{l}3.835-11.903 \\
1.015-4.931\end{array}$ & $\begin{array}{l}<0.001 \\
0.562\end{array}$ & $\begin{array}{l}9.516 \\
1.391\end{array}$ & $\begin{array}{l}3.959-22.876 \\
0.456-4.239\end{array}$ \\
\hline
\end{tabular}

Abbreviations: $\mathrm{cN}_{0}$, clinical lymph node negative; PTC, papillary thyroid carcinoma; CLMN, central lymph node metastasis; SMI, superb microvascular imaging; SWV, shear wave velocity; VAR, virtual touch tissue area ratio; $95 \% \mathrm{Cl}, 95 \%$ confidence interval.

number of positive lymph nodes, and extranodal extension in the ipsilateral central neck to estimate the risk of contralateral CLNM in patients with unilateral PTC, which obtained good discrimination and calibration. However, the pathological predictor (extranodal extension in the ipsilateral central) is determined postoperatively. It is difficult to help surgeons determine the extent of thyroid surgery.

The nomogram developed in our study utilized 6 available variables in the preoperative setting such as age, gender, tumor size, distance from the capsule, microcalcification, and $\mathrm{SWV}_{\text {mean }}$ to predict the probability of contralateral CLNM in patients with solitary and $\mathrm{cN}_{0}$ PTC. Age, gender, and tumor size have been repeatedly confirmed as the independent predictors of CLNM. ${ }^{26-28}$ Although the tumor size in this study was only $4-11 \mathrm{~mm}$ (most of them were papillary thyroid microcarcinoma), the nomogram confirmed the increase of tumor size as a large contributor to scores. Lim et $\mathrm{al}^{3}$ and Roti et $\mathrm{al}^{29}$ also demonstrated the predictive value of increasing tumor size in papillary thyroid microcarcinoma. Previous studies have confirmed that capsular invasion of PTC is closely related to CLNM. ${ }^{30,31}$ Hence, PTC patients with capsular invasion were excluded in this study and the distance from the capsule was observed. Our results indicated that the distance from the capsule was predictive for contralateral CLNM, which was in accordance with the study of Seong et al, ${ }^{32}$ who reported that a distance from the capsule $<1.9 \mathrm{~mm}$ was associated with CLNM in $\mathrm{cN}_{0}$ PTC patients. The presence of calcification is known to identify benign and 


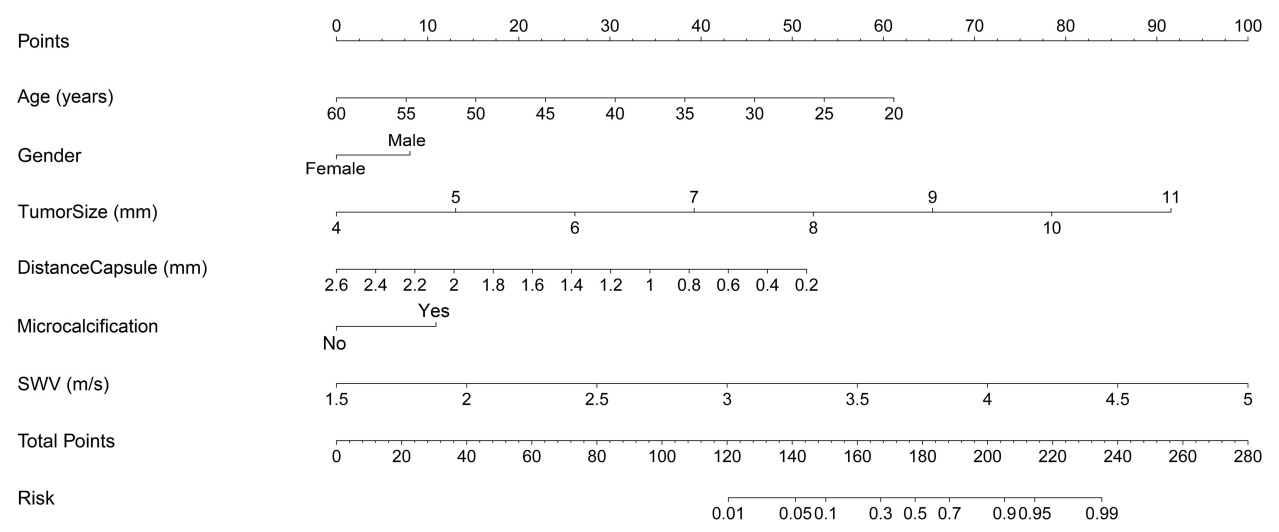

Figure 3 Nomogram for predicting the risk of contralateral CLMN in patients with solitary and $\mathrm{cN}_{0}$ PTC. The top row shows the point assignment for each variable. Rows 2-7 indicate the variables included in the nomogram. The bottom row shows the risk of contralateral CLMN. For example, when a 8 mm PTC with microcalcification is diagnosed in a 40 -year-old male patient. The distance between the tumor and capsule is $1 \mathrm{~mm}$, and the $S W V_{\text {mean }}$ of the tumor is $3.5 \mathrm{~m} / \mathrm{s}$. The total score is about 195 , which indicates that the probability of contralateral CLMN is about $80 \%$. $\mathrm{cN}_{0}$ : clinical lymph node negative.

Abbreviations: PTC, papillary thyroid carcinoma; CLMN, central lymph node metastasis; SWV, shear wave velocity.

A

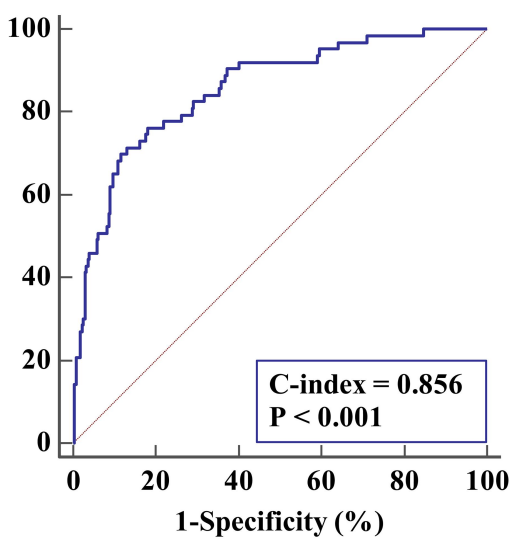

B

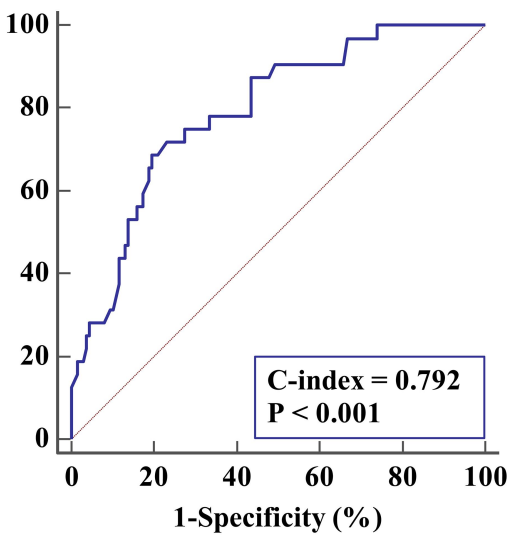

Figure 4 ROC for the discrimination of the nomogram. (A) for discrimination in the training cohort. The C-index is 0.856 ( $95 \% \mathrm{Cl} 0.8 \mathrm{I} 4$ to $0.89 \mathrm{I}$ ), demonstrating very good discrimination. (B) for discrimination in the external validation set. The C-index is 0.792 ( $95 \% \mathrm{Cl} 0.723$ to 0.850$)$, again demonstrating good discrimination.

Abbreviations: ROC, receiver operating characteristic curve; C-index, Harrell's concordance index; $95 \% \mathrm{Cl}, 95 \%$ confidence interval.

malignant thyroid tumors. However, its association with CLNM is still uncertain. ${ }^{15,16,18}$ In our study, microcalcification was an independent predictor for contralateral CLNM.

ARFI elastography as a supplement to ultrasonography is capable of evaluating the tissue stiffness non-invasively. The association between the stiffness of thyroid tumor and the risk of lymph node metastasis has been reported. ${ }^{18}$ In the present study, $\mathrm{SWV}_{\text {mean }}$ and VAR were associated with contralateral CLNM in univariate analysis. $\mathrm{SWV}_{\text {mean }}$ and VAR reveal the stiffness of the tumor itself and the adjacent thyroid parenchyma. On pathology, tissue fibrosis influences tumor progression by regulating soluble factors that induce inflammation and angiogenesis and stimulate cell growth and invasion. Tumor progression with cell proliferation and fibrosis would affect both tumor stiffness and aggressiveness including lymphatic metastasis. ${ }^{33}$ The invasion of adjacent tissues may lead to increased stiffness around the tumor. Hence, the area on VTI is larger than that on grayscale ultrasound. A positive association between the increased stiffness of thyroid tumor and LNM has been reported. ${ }^{16,34}$ However, VAR was not associated with contralateral CLNM after adjustment for other predictors by multivariate logistic analysis. The possible reason may be that the VAR is plotted manually, and the inevitable operating error may cause inaccurate measurement.

\section{Advantages of the Nomogram}

The principal advantage of our nomogram is that all the predictors are convenient to obtain from regular examinations preoperatively, which means a good application value 
in the clinical setting. Furthermore, this nomogram was verified to have good discrimination both in the training cohort (C-index, 0.856) and validation cohort (C-index, 0.792 ), which allows a wise and customized decision on the performance of contralateral CLNM in patients with solitary and $\mathrm{cN}_{0}$ PTC in the preoperative period.

\section{Limitations}

Some limitations are inevitable due to the retrospective study. The selection bias might present since only patients who underwent surgery were recruited. ARFI elastography was performed only for patients with suspicious PTC preoperatively. In addition, the interobserver variabilities of VAR and SWV on ARFI elastography were not assessed. The association between ARFI elastography and the status of contralateral CLNM needs to be validated on further studies.

\section{Conclusion}

In conclusion, we established a nomogram utilizing the features of ultrasound combined with ARFI elastography in predicting the likelihood of contralateral CLNM in patients with solitary and $\mathrm{cN}_{0}$ PTC preoperatively. The nomogram showed superior performance both in the training and validation cohort. Based on the quantified risk stratification, contralateral PCND may be considered when the patient has a high nomogram score.

\section{Ethical Approval}

Ethical approval for the study was obtained from the ethics committee of Yunnan Kungang Hospital (EC-202002031013).

\section{Informed Consent}

Written informed consent was obtained from all patients.

\section{Acknowledgments}

The authors wish to thank all the study participants, research staff and students who participated in this work.

\section{Author Contributions}

Ning Li and Ju-hua He contributed equally to this study and are co-first authors. Chao Song and Li-chun Yang are cocorresponding authors. Study design: Ning Li, Ju-hua He, Chao Song, and Li-chun Yang. Data collection and analysis: Ning Li, Ju-hua He, Hong-jiang Zhang, and Zhi-hai Li. Supervision: Chao Song and Li-chun Yang. Statistics: Ning Li, Ju-hua He, Chao Song, and Li-chun Yang. Manuscript writing: Ning Li, Ju-hua He, Chao Song, and Li-chun Yang.
Manuscript revision: Ning Li, Ju-hua He, Chao Song, and Lichun Yang. Approval of the manuscript: all authors. All authors made a significant contribution to the work reported, whether that is in the conception, study design, execution, acquisition of data, analysis and interpretation, or in all these areas; took part in drafting, revising or critically reviewing the article; gave final approval of the version to be published; have agreed on the journal to which the article has been submitted; and agree to be accountable for all aspects of the work.

\section{Funding}

There is no funding to report.

\section{Disclosure}

The authors declare that they have no conflict of interest.

\section{References}

1. Koo BS, Choi EC, Yoon YH, et al. Predictive factors for ipsilateral or contralateral central lymph node metastasis in unilateral papillary thyroid carcinoma. Ann Surg. 2009;249(5):840-844. doi:10.1097/ SLA.0b013e3181a40919.

2. Sugitani I, Fujimoto Y, Yamada K, et al. Prospective outcomes of selective lymph node dissection for papillary thyroid carcinoma based on preoperative ultrasonography. World J Surg. 2008;32 (11):2494-2502. doi:10.1007/s00268-008-9711-9.

3. Lim YC, Choi EC, Yoon YH, et al. Central lymph node metastases in unilateral papillary thyroid microcarcinoma. Br J Surg. 2009;96 (3):253-257. doi:10.1002/bjs.6484.

4. Roh JL, Kim JM, Park CI. Central cervical nodal metastasis from papillary thyroid microcarcinoma: pattern and factors predictive of nodal metastasis. Ann Surg Oncol. 2008;15(9):2482-2486. doi:10.1245/s10434-008-0044-6.

5. Haugen BR, Alexander EK, Bible KC, et al. 2015 american thyroid association management guidelines for adult patients with thyroid nodules and differentiated thyroid cancer: the american thyroid association guidelines task force on thyroid nodules and differentiated thyroid cancer. Thyroid. 2016;26(1):1-133. doi:10.1089/ thy.2015.0020.

6. Ito $\mathrm{Y}$, Tomoda $\mathrm{C}$, Uruno $\mathrm{T}$, et al. Clinical significance of metastasis to the central compartment from papillary microcarcinoma of the thyroid. World J Surg. 2006;30(1):91-99. doi:10.1007/s00268-0050113-y.

7. Giordano D, Valcavi R, Thompson GB, et al. Complications of central neck dissection in patients with papillary thyroid carcinoma: results of a study on 1087 patients and review of the literature. Thyroid. 2012;22(9):911-917. doi:10.1089/thy.2012.0011.

8. Garcia A, Palmer BJ, Parks NA, et al. Routine prophylactic central neck dissection for low-risk papillary thyroid cancer is not cost-effective. Clin Endocrinol (Oxf). 2014;81(5):754-761. doi:10.1111/cen.12506.

9. Mulla M, Schulte KM. Central cervical lymph node metastases in papillary thyroid cancer: a systematic review of imaging-guided and prophylactic removal of the central compartment. Clin Endocrinol (Oxf). 2012;76(1):131-136. doi:10.1111/j.1365-2265.2011.04162.x.

10. Kim E, Park JS, Son KR, et al. Preoperative diagnosis of cervical metastatic lymph nodes in papillary thyroid carcinoma: comparison of ultrasound, computed tomography, and combined ultrasound with computed tomography. Thyroid. 2008;18(4):411-418. doi:10.1089/ thy.2007.0269. 
11. Hwang HS, Orloff LA. Efficacy of preoperative neck ultrasound in the detection of cervical lymph node metastasis from thyroid cancer. Laryngoscope. 2011;121(3):487-491. doi:10.1002/lary.21227.

12. Kim SK, Chai YJ, Park I, et al. Nomogram for predicting central node metastasis in papillary thyroid carcinoma. J Surg Oncol. 2017;115(3):266-272. doi:10.1002/jso.24512.

13. Wang Y, Guan Q, Xiang J. Nomogram for predicting central lymph node metastasis in papillary thyroid microcarcinoma: a retrospective cohort study of 8668 patients. Int J Surg. 2018;55:98-102. doi:10.1016/j.ijsu.2018.05.023.

14. Yang Z, Heng Y, Lin J, et al. Nomogram for predicting central lymph node metastasis in papillary thyroid cancer: a retrospective cohort study of two clinical centers. Cancer Res Treat. 2020. doi:10.4143/ crt.2020.254

15. Yang Y, Chen C, Chen Z, et al. Prediction of central compartment lymph node metastasis in papillary thyroid microcarcinoma. Clin Endocrinol (Oxf). 2014;81(2):282-288. doi:10.1111/cen.12417.

16. Xu JM, Xu HX, Li XL, et al. A risk model for predicting central lymph node metastasis of papillary thyroid microcarcinoma including conventional ultrasound and acoustic radiation force impulse elastography. Medicine (Baltimore). 2016;95(3):e2558. doi:10.1097/ md.0000000000002558.

17. Park AY, Kim JA, Son EJ, et al. Shear-wave elastography for papillary thyroid carcinoma can improve prediction of cervical lymph node metastasis. Ann Surg Oncol. 2016;23(Suppl 5):722-729. doi:10.1245/s10434-016-5572-x.

18. Xu JM, Xu XH, Xu HX, et al. Prediction of cervical lymph node metastasis in patients with papillary thyroid cancer using combined conventional ultrasound, strain elastography, and acoustic radiation force impulse (ARFI) elastography. Eur Radiol. 2016;26 (8):2611-2622. doi:10.1007/s00330-015-4088-2.

19. Xu JM, Xu XH, Xu HX, et al. Conventional US, US elasticity imaging, and acoustic radiation force impulse imaging for prediction of malignancy in thyroid nodules. Radiology. 2014;272(2):577-586. doi:10.1148/radiol.14132438.

20. Harrell FE Jr, Lee KL, Mark DB. Multivariable prognostic models: issues in developing models, evaluating assumptions and adequacy, and measuring and reducing errors. Stat Med. 1996;15(4):361-387.

21. Harrell FE Jr, et al. Evaluating the yield of medical tests. JAMA. 1982;247(18):2543-2546. doi:10.1001/jama.1982.03320430047030

22. Al Afif A, Williams BA, Rigby $\mathrm{MH}$, et al. Multifocal papillary thyroid cancer increases the risk of central lymph node metastasis. Thyroid. 2015;25(9):1008-1012. doi:10.1089/thy.2015.0130.

23. Moo TA, Umunna B, Kato M, et al. Ipsilateral versus bilateral central neck lymph node dissection in papillary thyroid carcinoma. Ann Surg. 2009;250(3):403-408. doi:10.1097/SLA.0b013e3181b3adab.
24. Sun W, Lan X, Zhang H, et al. Risk factors for central lymph node metastasis in CN0 papillary thyroid carcinoma: a systematic review and meta-analysis. PLoS One. 2015;10(10):e0139021. doi:10.1371/ journal.pone.0139021.

25. Hei H, Song Y, Qin J. A nomogram predicting contralateral central neck lymph node metastasis for papillary thyroid carcinoma. J Surg Oncol. 2016;114(6):703-707. doi:10.1002/jso.24403.

26. Kim SK, Woo JW, Lee JH, et al. Role of BRAF V600E mutation as an indicator of the extent of thyroidectomy and lymph node dissection in conventional papillary thyroid carcinoma. Surgery. 2015;158 (6):1500-1511. doi:10.1016/j.surg.2015.05.016.

27. Thompson AM, Turner RM, Hayen A, et al. A preoperative nomogram for the prediction of ipsilateral central compartment lymph node metastases in papillary thyroid cancer. Thyroid. 2014;24 (4):675-682. doi:10.1089/thy.2013.0224.

28. Roh JL, Kim JM, Park CI. Central lymph node metastasis of unilateral papillary thyroid carcinoma: patterns and factors predictive of nodal metastasis, morbidity, and recurrence. Ann Surg Oncol. 2011;18(8):2245-2250. doi:10.1245/s10434-011-1600-z.

29. Roti E, Rossi R, Trasforini G, et al. Clinical and histological characteristics of papillary thyroid microcarcinoma: results of a retrospective study in 243 patients. J Clin Endocrinol Metab. 2006;91(6):2171-2178.

30. Kim JW, Roh JL, Gong G, et al. Extent of extrathyroidal extension as a significant predictor of nodal metastasis and extranodal extension in patients with papillary thyroid carcinoma. Ann Surg Oncol. 2017;24 (2):460-468. doi:10.1245/s10434-016-5594-4.

31. Kamaya A, Tahvildari AM, Patel BN, et al. Sonographic detection of extracapsular extension in papillary thyroid cancer. J Ultrasound Med. 2015;34(12):2225-2230. doi:10.7863/ultra.15.02006.

32. Seong CY, Chai YJ, Lee SM, et al. Significance of distance between tumor and thyroid capsule as an indicator for central lymph node metastasis in clinically node negative papillary thyroid carcinoma patients. PLoS One. 2018;13(7):e0200166. doi:10.1371/journal. pone. 0200166 .

33. Bierie B, Chung CH, Parker JS, et al. Abrogation of TGF-beta signaling enhances chemokine production and correlates with prognosis in human breast cancer. J Clin Invest. 2009;119(6):1571-1582. doi:10.1172/jci37480.

34. Jung WS, Kim JA, Son EJ, et al. Shear wave elastography in evaluation of cervical lymph node metastasis of papillary thyroid carcinoma: elasticity index as a prognostic implication. Ann Surg Oncol. 2015;22(1):111-116. doi:10.1245/s10434-014-3627-4.
Cancer Management and Research

\section{Publish your work in this journal}

Cancer Management and Research is an international, peer-reviewed open access journal focusing on cancer research and the optimal use of preventative and integrated treatment interventions to achieve improved outcomes, enhanced survival and quality of life for the cancer patient.
The manuscript management system is completely online and includes a very quick and fair peer-review system, which is all easy to use. Visit http://www.dovepress.com/testimonials.php to read real quotes from published authors. 